\section{Screening for asymptomatic STIs in HIV-infected men who have sex with men}

\begin{abstract}
We aimed to study the prevalence, characteristics and risk factors of asymptomatic sexually transmitted infections (STIs) in HIV-infected men who have sex with men (MSM). We conducted a prospective cross-sectional study, including asymptomatic HIV-infected MSM attending regular visits between December 2014 and December 2017. Of the 301 patients included, 60 patients $(19.9 \%)$ presented at least one STI. The most common STI was syphilis (33 of 69 STIs), followed by chlamydia (19 of 69), gonorrhoea (10 of 69), hepatitis C virus (4 of 69) and lymphogranuloma venereum (3 of 69). Illicit drug use during sex was the only variable significantly associated with the presence of an STI on multivariate analysis (OR 2.13; 95\% Cl 1.17-3.89). We were unable to identify a subgroup of patients where we could potentially avoid STI screening. Our findings support current guidelines that recommend routine screening for all HIV-infected MSM regardless of their self-reported sexual history.
\end{abstract}

International guidelines recommend at least annual screening for syphilis, gonorrhoea and chlamydia in all sexually active HIVinfected men who have sex with men (MSM). ${ }^{1-3}$ Lack of symptoms is common with an observed STIs point prevalence in asymptomatic HIV-infected MSM of $13 \%-16 \%$ in previous studies. ${ }^{4-9}$ While testing for STIs has increased in recent years, it remains far below guidelines' recommendations. ${ }^{10-12}$ We aimed to study the prevalence, characteristics and risk factors of asymptomatic STIs in HIVinfected MSM.

We conducted a prospective crosssectional study in a Spanish university hospital, including asymptomatic HIV-infected MSM (aged $\geq 17$ years) attending regular visits at the outpatient HIV clinic between December 2014 and December 2017. We excluded patients with STI symptoms and those treated with antibiotics in the last 30 days. All patients completed a self-administered questionnaire that included information about sexual behaviour, condom use and recreational drugs. We screened for gonorrhoea and chlamydia by multiplex real-time PCR tests in pharynx, rectum and first-void urine. We performed serologies for syphilis, hepatitis C virus and
Table 1 STIs detected in asymptomatic HIVinfected men who have sex with men

\begin{tabular}{lc}
\hline Type of STI & $\begin{array}{c}\text { Study cohort* } \\
\text { ( } \mathbf{n}=301)\end{array}$ \\
\hline $\begin{array}{l}\text { Syphilis } \\
\quad \text { Early latent }\end{array}$ & $93(11.0)$ \\
$\begin{array}{l}\text { Late latent or latent of unknown } \\
\text { duration }\end{array}$ & $24(8.0)$ \\
$\begin{array}{l}\text { Chlamydia trachomatis, serovars } \\
\text { D-K† }\end{array}$ & $19(6.3)$ \\
\hline Rectal & $12(4.0)$ \\
\hline Pharyngeal & $5(1.7)$ \\
\hline Urethral & $4(1.3)$ \\
\hline Neisseria gonorrhoeae & $10(3.3)$ \\
\hline Rectal & $6(2.0)$ \\
\hline Pharyngeal & $5(1.7)$ \\
\hline Urethral & $0(0.0)$ \\
\hline Hepatitis C virus & $4(1.3)$ \\
\hline LGV, rectal & $3(1.0)$ \\
\hline Hepatitis B virus & $0(0.0)$ \\
\hline
\end{tabular}

Data are presented as number of patients (\%).

* Seven patients tested positive for two STIs and one patient tested positive for four STIs.

†Two patients tested positive for $C$. trachomatis in two locations.

$\ddagger$ One patient tested positive for $N$. gonorrhoeae in two locations.

LGV, lymphogranuloma venereum.

hepatitis B virus. We performed a PCR test for hepatitis $\mathrm{C}$ virus following clinicians' criteria.

We assessed comparisons between groups by the Mann-Whitney $U$ test for quantitative variables and $\chi^{2}$ test based analyses for qualitative variables. We used logistic regression to estimate the ORs and associated 95\% CI for potential risk factors associated with the presence of any STI. To evaluate if we could potentially avoid STI screening in a subgroup of patients through a risk-based screening strategy, we developed a decision tree algorithm. We performed a sensitivity analysis using a cost-matrix for misclassification to consider the cost of misclassifying patients with an STI as uninfected using this decision tree.

During the study period, we included 301 patients. Four patients (1.3\%) were screened incompletely but were included for final analysis. In total, 60 patients $(19.9 \%)$ presented at least one of the screened STIs, diagnosing 69 STIs (table 1). Although 215 of 300 patients $(71.7 \%)$ reported previous STIs, only 77 of 278 patients $(27.7 \%)$ reported previous STI testing. Of the 96 patients who reported being in a monogamous relationship, 15 patients $(15.6 \%)$ tested positive for any STI. Of the 29 patients who reported always using a condom for oral and anal sex, three patients (10.3\%) had an STI. After adjustment for potential confounders on multivariate analysis, only illicit drug use during sex remained significantly associated with the presence of an STI (OR 2.13; 95\% CI 1.17 to 3.89). We were unable to develop a valid decision tree to identify patients that could avoid screening because our algorithm showed no stable solution for any cost-matrix value and too many patients with STIs would go undiagnosed. See online supplementary file 1 for detailed information about the baseline characteristics of our study cohort and the analysis of potential risk factors associated with STIs.

Our findings support current guidelines that recommend routine screening for all HIV-infected MSM regardless of their self-reported sexual history. Future public health strategies should consider the economic costs and cost-effectiveness associated with regular screening for STIs in all HIV-infected MSM.

\section{Rein Willekens $\odot{ }^{1,2}$ Irene Sánchez, ${ }^{1}$ Lucía Miguel, ${ }^{1}$ Juliana Esperalba, ${ }^{3}$ Judit Serra-Pladevall $\odot{ }^{3}$ Mario Martin, ${ }^{1}$ Jordi Navarro, ${ }^{1,4}$ Vicenç Falcó, ${ }^{1,2}$ Joaquín Burgos, ${ }^{1}$ Esteban Ribera, ${ }^{1}$ Estrella Caballero, ${ }^{3}$ Adrian Curran ${ }^{1}$}

'Department of Infectious Diseases, Vall d'Hebron Hospital, Barcelona, Spain

${ }^{2}$ Department of Medicine, Universitat Autònoma de Barcelona, Barcelona, Spain

${ }^{3}$ Microbiology Department, Vall d'Hebron Hospital, Barcelona, Spain

${ }^{4}$ Vall d'Hebron Research Institute, Barcelona, Spain

Correspondence to Dr Rein Willekens, Department of Infectious Diseases, Vall d'Hebron Hospital, Barcelona 08035, Spain; reinmorales@gmail.com

Handling editor Anna Maria Geretti

Contributors RW was responsible for study design, literature search, data collection, analysis, interpretation and manuscript writing. IS was responsible for study conception and design, data collection and interpretation, and manuscript review. LM, JE, JS-P, JN, $V F$, JB, ER and EC were responsible for data collection and interpretation, and manuscript review. MM was responsible for data analysis and manuscript review. AC was responsible for study conception and design, data collection, analysis, interpretation and manuscript review.

Funding This work has been partially supported by the SPANISH AIDS Research Network RD16/0025/0007 project as part of the Plan Nacional $\mathrm{R}+\mathrm{D}+\mathrm{I}$ and by ISCIII-Subdirección General de Evaluación y el Fondo Europeo de Desarrollo Regional.

Disclaimer The funders had no role in study design data collection, and interpretation, or the decision to submit the work for publication.

Competing interests None declared.

Patient consent for publication Not required.

Ethics approval The local ethics committee approved the study protocol (number: PR(AG)238/2014), and we obtained written informed consent from all patients. 
Provenance and peer review Not commissioned; externally peer reviewed.

(C) Author(s) (or their employer(s)) 2021. No commercial re-use. See rights and permissions. Published by BMJ.

- Additional material is published online only. To view please visit the journal online (http://dx.doi.org/ 10.1136/sextrans-2020-054560).

\section{A) Check for updates}

To cite Willekens R, Sánchez I, Miguel L, et al. Sex Transm Infect 2021;97:170-171.

Received 23 April 2020

Accepted 27 June 2020

Published Online First 4 August 2020

Sex Transm Infect 2021;97:170-171.

doi:10.1136/sextrans-2020-054560

\section{ORCID iDs}

Rein Willekens http://orcid.org/0000-0001-7791-3682 Judit Serra-Pladevall http://orcid.org/0000-0002-47982385

\section{REFERENCES}

1 European AIDS Clinical Society. EACS guidelines version 10.0, November 2019. Available: https://www. eacsociety.org/files/2019_guidelines-10.0_final.pdf [Accessed 20 Jun 2020].

2 Waters L, Lord E, Mackie N, et al. BHIVA/BASHH/FSRH guidelines for the sexual \& reproductive health of people living with HIV, 2017. Available: https://www. bhiva.org/file/zryuNVwnXcxMC/SRH-guidelines-forconsultation2017.pdf [Accessed 20 Jun 2020].

3 Workowski KA, Bolan GA, Centers for Disease Control and Prevention. Sexually transmitted diseases treatment guidelines, 2015. MMWR Recomm Rep 2015;64:1-137.

4 Rieg G, Lewis RJ, Miller LG, et al. Asymptomatic sexually transmitted infections in HIV-infected men who have sex with men: prevalence, incidence, predictors, and screening strategies. AIDS Patient Care STDS 2008;22:947-54

5 Heiligenberg M, Rijnders B, Schim van der Loeff MF, et al. High prevalence of sexually transmitted infections in HIV-infected men during routine outpatient visits in the Netherlands. Sex Transm Dis 2012:39:8-15.

6 Spinner CD, Boesecke C, Jordan C, et al. Prevalence of asymptomatic sexually transmitted infections in HIV-positive men who have sex with men in Germany: results of a multicentre cross-sectional study. Infection 2018:46:341-7.
7 Keaveney S, Sadlier C, O'Dea S, O'Dea S, et al. High prevalence of asymptomatic sexually transmitted infections in HIV-infected men who have sex with men: a stimulus to improve screening. Int I STD AIDS 2014;25:758-61.

8 Braun DL, Marzel A, Steffens D, et al. High rates of subsequent asymptomatic sexually transmitted infections and risky sexual behavior in patients initially presenting with primary human immunodeficiency virus-1 infection. Clin Infect Dis 2018:66:735-42.

9 Sprenger K, Evison JM, Zwahlen M, et al. Sexually transmitted infections in HIV-infected people in Switzerland: cross-sectional study. PeerJ 2014;2:e537.

10 Mattson CL, Bradley H, Beer L, et al. Increased sexually transmitted disease testing among sexually active persons receiving medical care for human immunodeficiency virus infection in the United States, 2009-2013. Clin Infect Dis 2017:64:629-34.

11 Patel MR, Brooks JT, Tie Y, et al. Prevalence of gonorrhea and Chlamydia testing by anatomical site among men who have sex with men in HIV medical care, United States, 2013-2014. Sex Transm Dis 2018;45:25-7.

12 Li J, Armon C, Palella FJ, et al. Chlamydia and gonorrhea incidence and testing among patients in the HIV outpatient study, 2007-2017. Clin Infect Dis 2019. 